\section{Association between osteoporosis and statins therapy}

Statins therapy is found to be associated with a decreased risk of osteoporosis. ${ }^{12}$ Moreover, a number of observational studies reported that statins therapy was associated with a decreased risk of osteoporotic fractures, ${ }^{34}$ but other studies did not. ${ }^{5} 6$ Some points are discussed here.

First, a study conducted by Leutner et $\mathrm{al}^{7}$ published in Annals of the Rheumatic Diseases reported that low dose of statins therapy was associated with a decreased risk of osteoporosis, but high dose of statins therapy was associated with an increased risk of osteoporosis. Second, osteoporosis is often under-diagnosed and under-treated, ${ }^{8}$ even though it might cause serious clinical problems and even though multiple effective medications are available now. Osteoporosis has placed some populations at risk of osteoporotic fractures. Leutner et al's study gives a hint that high dose of statins therapy correlates with the risk of osteoporosis and maybe subsequent fractures. However, a cohort study reported that people taking high-potency statins such as atorvastatin or rosuvastatin were at lower risk of developing osteoporotic fractures when compared with those taking simvastatin. ${ }^{3} \mathrm{~A}$ case-control study by Cheng et al reported that current use of statins seemed to have a protective effect against hip fracture in older people (adjusted OR 0.73 , 95\% CI 0.65 to 0.82$){ }^{4}$ There was also a dose-dependent effect of statins use on the protective effect of hip fracture in Cheng et al's study. ${ }^{4}$ That is, the higher the dose of statins use, the lower the risk of hip fracture. This finding was not compatible with Leutner et al's study showing that high dose of statins use was associated with an increased risk of osteoporosis. ${ }^{7}$ Third, blood lipid and bone mineral density are dynamic change. In clinical practice, the initial levels of blood lipid would determine which potency of statins should be used. Once the treatment goal of blood lipid is achieved, the dose of statins can be reduced. If the treatment goal is not achieved, the dose of statins can be increased. In addition, bone mineral density cannot be measured every day. It is difficult to assess that bone mineral density is affected by low dose or high dose of statins in retrospective studies. Only randomised controlled trials have a chance to investigate whether the dosage or the potency of statins would affect bone mineral density. Then the causation between statins therapy and osteoporosis can be clarified. Fourth, currently there is no research to definitely prove the causal relationship between statins therapy and osteoporosis. The US Preventive Services Task Force does not recommend that persons on statins therapy should screen for osteoporosis to prevent osteoporotic fractures. ${ }^{9}$ It indicates that at present persons taking statins do not need to worry about the risk of osteoporosis. Finally, I agree with Leutner et al's comments that future studies should focus on the causal relationship between the dosage-potency of statins and osteoporosis rather than the association.

Shih-Wei Lai $\odot^{1,2}$

${ }^{1}$ College of Medicine, China Medical University, Taichung, Taiwan

${ }^{2}$ Department of Family Medicine, China Medical University Hospital, Taichung, Taiwan

Correspondence to Dr Shih-Wei Lai, Family Medicine, China Medical University Hospital, 404 Taichung City, Taiwan; wei@mail.cmuh.org.tw

Handling editor Josef S Smolen

Contributors S-WL contributed to the conception of the article, initiated the draft of the article and has approved the final draft submitted.

Funding The authors have not declared a specific grant for this research from any funding agency in the public, commercial or not-for-profit sectors.

Competing interests None declared.

Patient consent for publication Not required.

Provenance and peer review Not commissioned; internally peer reviewed.

(c) Author(s) (or their employer(s)) 2019. No commercial re-use. See rights and permissions. Published by BMJ.

\section{Check for updates}

To cite Lai S-W. Ann Rheum Dis Epub ahead of print: [please include Day Month Year]. doi:10.1136/annrheumdis-2019-216464

Received 10 October 2019

Accepted 13 October 2019

Ann Rheum Dis 2019:0:1. doi:10.1136/annrheumdis-2019-216464

\section{ORCID iD}

Shih-Wei Lai http://orcid.org/0000-0002-7420-1572

\section{REFERENCES}

1 Lin T-K, Chou P, Lin C-H, et al. Long-Term effect of statins on the risk of newonset osteoporosis: a nationwide population-based cohort study. PLoS One 2018;13:e0196713.

2 Lin S-M, Wang J-H, Liang C-C, et al. Statin use is associated with decreased osteoporosis and fracture risks in stroke patients. J Clin Endocrinol Metab 2018; 103:3439-48

3 Lin T-K, Liou Y-S, Lin C-H, et al. High-Potency statins but not all statins decrease the risk of new-onset osteoporotic fractures: a nationwide population-based longitudinal cohort study. Clin Epidemiol 2018;10:159-65.

4 Cheng K-C, Liao K-F, Lin C-L, et al. Case-Control study examining the association between hip fracture risk and statins therapy in old people. Medicine 2019:98:e17476.

5 Peña JM, Aspberg S, MacFadyen J, et al. Statin therapy and risk of fracture: results from the JUPITER randomized clinical trial. JAMA Intern Med 2015:175:171-7.

6 van Staa TP, Wegman S, de Vries F, et al. Use of statins and risk of fractures. JAMA 2001:285:1850-5.

7 Leutner M, Matzhold C, Bellach L, et al. Diagnosis of osteoporosis in statintreated patients is dose-dependent. Ann Rheum Dis 2019. doi:10.1136/ annrheumdis-2019-215714

8 Nayak S, Roberts MS, Greenspan SL. Factors associated with diagnosis and treatment of osteoporosis in older adults. Osteoporos Int 2009;20:1963-7.

9 Curry SJ, Krist AH, Owens DK, et al. Screening for osteoporosis to prevent fractures: US preventive services Task force recommendation statement. JAMA 2018:319:2521-31. 